\title{
Non-steroidal anti-inflammatory drugs (NSAIDs) for cancer-related pain in children and adolescents (Review)
}

Cooper TE, Heathcote LC, Anderson B, Grégoire MC, Ljungman G, Eccleston C

Cooper TE, Heathcote LC, Anderson B, Grégoire MC, Ljungman G, Eccleston C.

Non-steroidal anti-inflammatory drugs (NSAIDs) for cancer-related pain in children and adolescents.

Cochrane Database of Systematic Reviews 2017, Issue 7. Art. No.: CD012563.

DOI: 10.1002/14651858.CD012563.pub2.

www.cochranelibrary.com

Non-steroidal anti-inflammatory drugs (NSAIDs) for cancer-related pain in children and adolescents (Review) Copyright $\odot 2019$ The Cochrane Collaboration. Published by John Wiley \& Sons, Ltd. 
ABSTRACT 1

PLAIN LANGUAGE SUMMARY

BACKGROUND

OBJECTIVES

METHODS

RESULTS

Figure 1.

DISCUSSION

AUTHORS' CONCLUSIONS

ACKNOWLEDGEMENTS

REFERENCES

CHARACTERISTICS OF STUDIES

APPENDICES

WHAT'S NEW

HISTORY

CONTRIBUTIONS OF AUTHORS

DECLARATIONS OF INTEREST

SOURCES OF SUPPORT

DIFFERENCES BETWEEN PROTOCOL AND REVIEW

NOTES

INDEX TERMS

\section{TABLE OF CONTENTS}


[Intervention Review]

\title{
Non-steroidal anti-inflammatory drugs (NSAIDs) for cancer-related pain in children and adolescents
}

\author{
Tess E Cooper1 ${ }^{1}$ Lauren C Heathcote², Brian Anderson 3 , Marie-Claude Grégoire4, Gustaf Ljungman5, Christopher Eccleston6,7,8
}

1Cochrane Kidney and Transplant, Centre for Kidney Research, The Children's Hospital at Westmead, Westmead, Australia. 2Department of Anesthesiology, Perioperative and Pain Medicine, Stanford University, Palo Alto, California, USA. 3Paediatric Intensive Care Unit, Starship Children's Hospital, Auckland, New Zealand. ${ }^{4}$ Paediatric Palliative Care, Department of Paediatrics, IWK Health Centre, Dalhousie University, Halifax, Canada. 5Paediatric Oncology, Department of Women's and Children's Health, Uppsala University, Uppsala, Sweden. ${ }^{6}$ Centre for Pain Research, University of Bath, Bath, UK. ${ }^{7}$ Cochrane Pain, Palliative and Supportive Care Group, Pain Research Unit, Churchill Hospital, Oxford, UK. 8Department of Clinical and Health Psychology, Ghent University, Ghent, Belgium

Contact: Tess E Cooper, Cochrane Kidney and Transplant, Centre for Kidney Research, The Children's Hospital at Westmead, Westmead, NSW, 2145, Australia. tess.cooper@sydney.edu.au.

Editorial group: Cochrane Pain, Palliative and Supportive Care Group.

Publication status and date: Stable (no update expected for reasons given in 'What's new'), published in Issue 10, 2019.

Citation: Cooper TE, Heathcote LC, Anderson B, Grégoire MC, Ljungman G, Eccleston C. Non-steroidal anti-inflammatory drugs (NSAIDs) for cancer-related pain in children and adolescents. Cochrane Database of Systematic Reviews 2017, Issue 7. Art. No.: CD012563. DOI: 10.1002/14651858.CD012563.pub2.

Copyright @ 2019 The Cochrane Collaboration. Published by John Wiley \& Sons, Ltd.

\section{A B S T R A C T}

\section{Background}

Pain is a common feature of childhood and adolescence around the world, and for many young people, that pain is chronic. The World Health Organization (WHO) guidelines for pharmacological treatments for persisting pain in children acknowledge that pain in children is a major public health concern of high significance in most parts of the world. Views on children's pain have changed over time and relief of pain is now seen as important. In the past, pain was largely dismissed and was frequently left untreated, and it was assumed that children quickly forgot about painful experiences.

We designed a suite of seven reviews in chronic non-cancer pain and cancer pain (looking at antidepressants, antiepileptic drugs, non-steroidal anti-inflammatory drugs, opioids, and paracetamol as priority areas) to review the evidence for children's pain using pharmacological interventions.

As one of the leading causes of mortality and morbidity for children and adolescents in the world today, childhood cancer (and its associated pain) is a major health concern. Specific mortality and morbidity data relating to children are not currently identified. All childhood cancer rates are on the rise; for example, in the USA approximately 10,380 children aged under 15 years were expected to be diagnosed with cancer by the end of 2016. However, with survival rates also increasing, over $80 \%$ of paediatric cancer patients are expected to survive for five years or more, thus identifying the need to address pain management in this population.

Cancer pain in infants, children, and adolescents is primarily nociceptive pain with negative long term effects. Cancer-related pain is generally caused directly by the tumour itself such as compressing on the nerve or inflammation of the organs. Cancer-related pain generally occurs as a result of perioperative procedures, nerve damage caused by radiation or chemotherapy treatments, or mucositis. However, this review focused on pain caused directly by the tumour itself such as nerve infiltration, external nerve compression, and other inflammatory events.

Non-steroidal anti-inflammatory drugs (NSAIDs) are used to treat pain, reduce fever, and for their anti-inflammatory properties. They are commonly used within paediatric pain management. NSAIDs are currently licensed for use in western countries, however not approved for infants aged under three months. Primary adverse effects include gastrointestinal issues and possible renal impairment with long term use. Other adverse effects in children include diarrhoea, headache, nausea, constipation, rash, dizziness, and abdominal pain. 


\section{Objectives}

To assess the analgesic efficacy, and adverse events, of non-steroidal anti-inflammatory drugs (NSAIDs) used to treat cancer-related pain in children and adolescents aged from birth and 17 years, in any setting.

\section{Search methods}

We searched the Cochrane Central Register of Controlled Trials (CENTRAL) via the Cochrane Register of Studies Online, MEDLINE via Ovid, and Embase via Ovid from inception to 21 February 2017. We also searched the reference lists of retrieved studies and reviews, and searched online clinical trial registries.

\section{Selection criteria}

Randomised, double-blind trials of any dose, and any route, treating cancer-related pain in children and adolescents, comparing NSAIDs with placebo or an active comparator.

\section{Data collection and analysis}

Two review authors independently assessed studies for eligibility. We planned to use dichotomous data to calculate risk ratio and number needed to treat for one additional event, using standard methods. We planned to assess GRADE (Grading of Recommendations Assessment, Development and Evaluation) and planned to create a 'Summary of findings' table.

\section{Main results}

No studies were eligible for inclusion in this review.

There is no evidence to support or refute the use of NSAIDs for treating cancer-related pain in children and adolescents.

\section{Authors' conclusions}

There is no evidence from randomised controlled trials to support or refute the use of NSAIDs to treat chronic cancer-related pain in children and adolescents. We are unable to comment about efficacy or harm from the use of NSAIDs to treat chronic cancer-related pain in children and adolescents.

\section{PLAIN LANGUAGE SUMMARY}

\section{NSAIDs for cancer-related pain in children and adolescents}

\section{Bottom line}

We are uncertain whether NSAIDs will provide pain relief for cancer-related pain in children or adolescents.

\section{Background}

Childhood cancer is one of the leading causes of disease and death for children and adolescents in the world today. Its associated pain is a major health concern and specific data for children are not currently well known.

Cancer pain in infants, children, and adolescents is primarily nerve pain with negative long term effects. Cancer-related pain is generally caused directly by the tumour itself such as nerve infiltration, external nerve compression, and other inflammatory events.

NSAIDs are used to treat pain or reduce fever, and are commonly used in children. NSAIDs are currently licensed for use in western countries, but they are not approved for infants aged under three months. The key side effects of NSAIDs are stomach problems and possible damage to kidneys following long term use. Other side effects in children include diarrhoea, headache, nausea, constipation, rash, dizziness, flatulence, stomach pain, and indigestion.

\section{Key results}

In February 2017 we searched for randomised controlled clinical trials where any NSAIDs were used to treat any cancer-related pain in people aged from birth to 17 years. We found no studies that met the requirements for this review. Several studies tested NSAIDs on adults in chronic pain, but none in participants aged from birth to 17 years.

\section{Quality of the evidence}

We planned to rate the quality of the evidence from studies using four levels: very low, low, moderate, or high. Very low quality evidence means that we are very uncertain about the results. High quality evidence means that we are very confident in the results.

We were unable to rate the quality of the evidence as there was no evidence from randomised controlled trials to support or refute the suggestion that NSAIDs in any dose will reduce chronic cancer-related pain in children or adolescents. 


\section{B A C K G R O U N D}

Pain is a common feature of childhood and adolescence around the world, and for many young people, that pain is chronic. The World Health Organization (WHO) guidelines for pharmacological treatments for persisting pain in children acknowledge that pain in children is a major public health concern of high significance in most parts of the world (WHO 2012). Views on children's pain have changed over time and relief of pain is now seen as important. In the past, pain was largely dismissed and was frequently left untreated, and it was assumed that children quickly forgot about painful experiences. Since the 1970s, studies comparing child and adult pain management revealed a variety of responses to pain, fuelling the need to focus on paediatric pain in more depth (Caes 2016).

Infants (birth to 12 months), children (1 to 9 years), and adolescents (10 to 18 years) (WHO 2012) account for $27 \%$ (1.9 billion) of the world's population (United Nations 2017), and the proportion of those aged up to 14 years varies from 12\% (in Hong Kong) to $50 \%$ (in Niger) (World Bank 2016). However, we know little about the pain management needs of this population. For example, in the Cochrane Library, approximately 12 reviews produced by the Cochrane Pain, Palliative and Supportive Care (PaPaS) Review Group in the past 18 years have been specifically concerned with children and adolescents, compared to over 100 reviews specific to adults. Additional motivating factors for investigating children's pain include the vast amount of unmanaged pain in the paediatric population and new technologies and treatments being developed. We convened an international group of leaders in paediatric pain to design a suite of seven reviews in chronic pain and cancer pain (looking at antidepressants, antiepileptic drugs, non-steroidal anti-inflammatory drugs (NSAIDs), opioids, and paracetamol as priority areas) to review the evidence under a programme grant for children's pain using pharmacological interventions in children and adolescents (Appendix 1).

This review is based on a template for reviews of pharmacotherapies used to relieve pain in infants, children and adolescents. The aim is for all reviews to use the same methods, based on new criteria for what constitutes reliable evidence (Moore 2010a; Moore 2012; Appendix 2). This review focuses on NSAIDs to treat cancer pain.

\section{Description of the condition}

This review focused on pain that children and adolescents experience as a result of any type of cancer.

The type of cancer pain in infants, children and adolescents is primarily nociceptive pain (Ljungman 1996), and generally occurs as a result of perioperative procedures and treatments. In addition, nerve damage caused by radiation or chemotherapy (WHO 2012) is also common. However, the tumour itself can also cause nerve infiltration, external nerve compression, and other painful inflammatory events such as distention (WHO 2012).

Whilst diagnostic and perioperative procedures performed for cancer treatment are a known common cause of pain in these patients (Ripamonti 2008), this review did not cover perioperative pain or adverse effects of treatments such as mucositis. We focused on pain caused directly by the tumour itself such as tissue damage, nerve infiltration, external nerve compression and other inflammatory events.

As one of the leading causes of mortality and morbidity in the world today, childhood cancer (and its associated pain) is a major health concern. The WHO predicts 14 to 15 million new cases of cancer across all ages to arise by 2020 (Frankish 2003; Ripamonti 2008), accounting for approximately 8.2 million deaths worldwide (WHO 2011). Specific mortality and morbidity data relating to children were not identified.

Worldwide childhood cancer statistics are difficult to estimate, particularly when examining both developed and developing counties. However, cancer is the leading cause of death in developed countries (WHO 1998). In the European region, leukaemia (34.1\%), central nervous system (CNS) tumours (22.6\%), and lymphomas (11.5\%) are the largest cancer diagnostic groups in the paediatric population (birth to 15 years) (Kaatsch 2010). In the USA, childhood cancer is the second leading cause of death (excluding neonates) (after injury), with leukaemia (30\%), CNS tumours or brain and other CNS tumours (26\%), and neuroblastoma (6\%) as the leading types of diagnosed cancers (ACS 2015). All childhood cancer rates are on the rise; for example, in the USA approximately 10,380 children under the age of 15 years were expected to be diagnosed with cancer by the end of 2016 (ACS 2015). However, with survival rates also increasing, over $80 \%$ of paediatric cancer patients are expected to survive for five years or more (ACS 2015). In the developing world, the incidence of cancer is difficult to estimate due to poor reporting, diagnostic facilities and hospital statistics. It is known that Burkitt lymphoma, non-Hodgkin lymphoma, nephroblastoma, retinoblastoma, and rhabdomyosarcoma are among the most common cancers in children across African regions (Tanko 2009). In Asian regions, leukaemias and CNS tumours are among the most common childhood cancers (IARC 2008).

\section{Description of the intervention}

NSAIDs are used for the treatment of pain and fever reduction for their anti-inflammation properties. They are commonly used within paediatric pain management (Blanca-López 2015). The two main types of NSAIDs are selective and nonselective, which refer to the ability of the NSAID to inhibit specific types of COX enzymes (Misurac 2013). NSAIDs are currently licensed for use in western countries, but are not approved for infants aged under three months (WHO 2012). NSAIDs are also widely used for patent ductus arteriosus (PDA) closure in neonates.

Currently available NSAIDs include: aceclofenac, acetylsalicylic acid, celecoxib, choline magnesium trisalicylates diclofenac, etodolac, etoricoxib, fenoprofen, ibuprofen, indometacin, ketoprofen, ketorolac, mefenamic acid, meloxicam, nabumetone, naproxen, parecoxib, phenylbutazone, piroxicam, sulindac, tenoxicam, and tiaprofenic acid (BNF 2016).

NSAIDs are used in a variety of doses and are commonly prescribed to children with pain as an oral tablet or liquid formulation. The recommended dose for ibuprofen (for example) is 5 to $10 \mathrm{mg} / \mathrm{kg}$ every six to eight hours with a maximum daily dose of $1200 \mathrm{mg}$. Additionally, for naproxen, a maximum dose of $1000 \mathrm{mg}$ per day is recommended (WHO 2012). The recommendation for paediatric patients is to use the lowest dose, for the shortest duration possible to control symptoms (NICE 2015); hence, NSAIDs are also used in 
conjunction with paracetamol to reduce the amount administered to children (WHO 2012).

The two primary adverse effects of NSAIDs are renal impairment and gastrointestinal issues (NICE 2015). Common side effects in children include diarrhoea, headache, nausea, constipation, rash, dizziness, flatulence, abdominal pain, and dyspepsia (WHO 2012). Other adverse effects include hepatic function impairment, contraindications with allergic disorders (hypersensitivity to aspirin, asthma, angioedema, urticaria, rhinitis), cardiac impairment, Reye's syndrome, antiplatelet effects, coagulation defects, and dangerous environmental harms (particularly seen in diclofenac). The long-term safety of the use of NSAIDs in children is unclear (Blanca-López 2015). However, some safety assessments of ibuprofen in children have been compared with paracetamol and not found a significant increased risk in serious adverse events or main causes of hospitalisation (acute gastrointestinal bleeding, acute renal failure, anaphylaxis, or Reye's syndrome) (Lesko 1995; Lesko 1997; Lesko 1999).

\section{How the intervention might work}

One current hypothesis is that damage to the peripheral nerves is followed by an inflammatory reaction that relates to increased production of prostaglandins, amplifying sodium currents and calcium influx in peripheral nociceptive neurons, and enhancing neurotransmitter release in the CNS and depolarisation of secondorder nociceptive neurons (Vo 2009). Preclinical data suggest an immune pathogenesis of neuropathic pain, but clinical evidence of a central role of the immune system is less clear (Calvo 2012). NSAIDs inhibit the production of prostaglandins, and thus could lessen the peripheral and central sensory hypersensitivity that occurs with nerve injury-associated inflammation. NSAIDs have been shown to reduce sensory hypersensitivity in animal models (Hasnie 2007; Kawakami 2002).

\section{Why it is important to do this review}

The paediatric population is at risk of inadequate management of pain (AMA 2013). Some conditions that would be aggressively treated in adults are being managed with insufficient analgesia in the younger populations (AMA 2013). Although there have been repeated calls for best evidence to treat children's pain, such as Eccleston 2003, there are no easily available summaries of the most effective paediatric pain relief.

This Cochrane Review will form part of a Programme Grant to address the unmet needs of people with chronic pain, commissioned by the National Institute for Health Research (NIHR) in the UK. This topic was identified in June 2015 during consultation with experts in paediatric pain. Please see Appendix 1 for full details of the meeting. The standards used to assess evidence in chronic pain trials have changed substantially in recent years, with particular attention being paid to trial duration, withdrawals, and statistical imputation following withdrawal, all of which can substantially alter estimates of efficacy. The most important change is to encourage a move from using average pain scores, or average change in pain scores, to the number of people who have a large decrease in pain (by at least 50\%). Pain intensity reduction of $50 \%$ or more has been shown to correlate with improvements in comorbid symptoms, function, and quality of life (Moore 2011a). These standards are set out in the reference guide for pain studies (AUREF 2012).

\section{O B JECT IVES}

To assess the analgesic efficacy, and adverse events, of nonsteroidal anti-inflammatory drugs (NSAIDs) used to treat cancerrelated pain in children and adolescents aged from birth to 17 years, in any setting.

\section{METHODS}

\section{Criteria for considering studies for this review}

\section{Types of studies}

We planned to only include randomised controlled trials (RCTs), with or without blinding, and participant or observer reported outcomes.

Full journal publication was required, with the exception of online clinical trial results, summaries of otherwise unpublished clinical trials and abstracts with sufficient data for analysis. We planned to include studies published in any language. We excluded abstracts (usually meeting reports) or unpublished data, non-randomised studies, studies of experimental pain, case reports, and clinical observations.

\section{Types of participants}

We planned to include studies of infants, children, and adolescents aged from birth to 17 years, who have (one or more) cancer and experience pain directly related to the condition.

We planned to include studies of participants with more than one type of cancer pain, and to analyse results according to the primary condition.

We excluded studies of perioperative pain, short-term infection pain, short-term injury or trauma pain, acute pain, functional abdominal pain, burn pain, musculoskeletal pain, headache and migraine, sickle cell disease acute crisis pain, mucositis, or any other chronic non-cancer pain.

\section{Types of interventions}

We planned to include studies reporting interventions prescribing NSAIDs for the relief of cancer pain; by any route, in any dose, with comparison to a placebo or any active comparator.

\section{Types of outcome measures}

Studies had to report pain assessment as either a primary or secondary outcome to be eligible for inclusion in this review, as well as meeting the other selection criteria.

We planned to include trials measuring pain intensity and pain relief assessed using validated tools such as numerical rating scale (NRS), visual analogue scale (VAS), Faces Pain Scale - Revised (FPS$\mathrm{R})$, Colour Analogue Scale (CAS), or any other validated rating scale.

We were particularly interested in Paediatric Initiative on Methods, Measurement, and Pain Assessment in Clinical Trials (PedIMMPACT) definitions for moderate and substantial benefit in chronic pain studies (PedIMMPACT 2008). These are defined as: at least $30 \%$ pain relief over baseline (moderate); at least $50 \%$ pain relief over baseline (substantial); much or very much improved on Patient Global Impression of Change scale (PGIC; moderate); very much improved on PGIC (substantial). 
These outcomes are different from those used in most earlier reviews, concentrating as they do on dichotomous outcomes where pain responses do not follow a normal (Gaussian) distribution. People with chronic pain desire high levels of pain relief, ideally more than $50 \%$ pain intensity reduction, and ideally having no worse than mild pain (Moore 2013a; O'Brien 2010).

We also planned to record any reported adverse events. We also planned to report the timing of outcome assessments.

\section{Primary outcomes}

1. Participant-reported pain relief of $30 \%$ or greater.

2. Participant-reported pain relief of $50 \%$ or greater.

3. PGIC much or very much improved.

In the absence of self-reported pain, we planned to consider the use of 'other-reported' pain, typically an observer such as a parent, carer, or healthcare professional (Stinson 2006; Von Baeyer 2007).

\section{Secondary outcomes}

We identified the following with reference to the PedIMMPACT recommendations, which suggest core outcome domains and measures for consideration in paediatric acute and chronic/ recurrent pain clinical trials (PedIMMPACT 2008):

1. carer global impression;

2. requirement for rescue analgesia;

3. sleep duration and quality;

4. acceptability of treatment;

5. physical functioning as defined by validated scales;

6. quality of life as defined by validated scales;

7. any adverse events;

8. withdrawals due to adverse events; and

9. any serious adverse event. Serious adverse events typically include any untoward medical occurrence or effect that at any dose results in death, is life-threatening, requires hospitalisation or prolongation of existing hospitalisation, results in persistent or significant disability or incapacity, is a congenital anomaly or birth defect, is an 'important medical event' that may jeopardise the patient, or may require an intervention to prevent one of the above characteristics or consequences.

\section{Search methods for identification of studies}

The authors and Information Specialist developed the search strategy, based on previous strategies used within the PaPaS Review Group, and we carried out the searches. We also sought advice from the Cochrane Childhood Cancer Group.

\section{Electronic searches}

We searched the following databases:

- Cochrane Central Register of Controlled Trials (CENTRAL) (via the Cochrane Library) searched on 21/2/2017;

- MEDLINE (via Ovid) 1947 to February week 2 2017;

- Embase (via Ovid) 1974 to 21/2/2017.

We used medical subject headings (MeSH) or equivalent and text word terms. We restricted our search for RCTs and clinical trials. There were no language restrictions. There were no date restrictions. The focus of the key words in our search terms was on cancer pain and NSAIDs. Searches were tailored to individual databases. The search strategies for MEDLINE, Embase and CENTRAL are presented in Appendix 3; Appendix 4 and Appendix 5 respectively.

\section{Searching other resources}

We searched clinicaltrials.gov (www.clinicaltrials.gov) and the WHO International Clinical Trials Registry Platform (ICTRP) (apps.who.int/trialsearch/) on 21 February 2017 for ongoing trials. In addition, we checked reference lists of reviews and retrieved articles for additional studies, and performed citation searches on key articles. We planned to contact experts in the field for unpublished and ongoing trials. We planned to contact study authors where necessary for additional information.

\section{Data collection and analysis}

We planned to perform separate analyses according to particular types of cancer. We planned to combine different cancer types in analyses for exploratory purposes only.

\section{Selection of studies}

Two review authors independently determined eligibility by reading the abstract of each study identified by the search. Independent review authors eliminated studies that clearly did not satisfy inclusion criteria, and obtained full copies of the remaining studies. Two review authors read these studies independently to select relevant studies, and in the event of disagreement, a third author adjudicated. We did not anonymise the studies in any way before assessment. We included a PRISMA flow chart in the full review which shows the status of identified studies (Moher 2009) as recommended in part 2, section 11.2.1 of the Cochrane Handbook for Systematic Reviews of Interventions (Higgins 2011). We planned to include studies in the review irrespective of whether measured outcome data were reported in a 'usable' way.

\section{Data extraction and management}

We planned to obtain full copies of the studies and two authors planned to independently carry out data extraction. Where available, data extraction would include information about the type of cancer, number of participants treated, drug and dosing regimen, study design (placebo or active control), study duration and followup, analgesic outcome measures and results, withdrawals, and adverse events (participants experiencing any adverse event, or serious adverse event). We planned to collate multiple reports of the same study, so that each study rather than each report was to be the unit of interest in the review. We planned to collect characteristics of the included studies in sufficient detail to populate a 'Characteristics of included studies' table.

We planned to use a template data extraction form and check for agreement before entry into Cochrane's statistical software Review Manager (version 5.3) (Review Manager 2014).

If a study had more than two intervention arms, we planned to only include in the review intervention groups and control groups that met the eligibility criteria. If multi-arm studies were included, we planned to analyse multiple intervention groups in an appropriate way to avoid arbitrary omission of relevant groups and doublecounting of participants. 


\section{Assessment of risk of bias in included studies}

Two authors planned to independently assess risk of bias for each study, using the criteria outlined in the Cochrane Handbook for Systematic Reviews of Interventions (Higgins 2011).

We planned to complete a 'Risk of bias' table for each included study using the 'Risk of bias' tool in RevMan (Review Manager 2014).

We planned to assess the following for each study. Any disagreements were to be resolved by discussion between review authors and where necessary, a third review author.

1. Random sequence generation (checking for possible selection bias). We planned to assess the method used to generate the allocation sequence as: low risk of bias (ie, any truly random process, for example random number table; computer random number generator); or unclear risk of bias (when the method used to generate the sequence was not clearly stated). We excluded studies at high risk of bias that used a non-random process (eg, odd or even date of birth; hospital or clinic record number).

2. Allocation concealment (checking for possible selection bias). The method used to conceal allocation to interventions prior to assignment determines whether intervention allocation could have been foreseen in advance of, or during, recruitment, or changed after assignment. We planned to assess the methods as: low risk of bias (eg, telephone or central randomisation; consecutively numbered, sealed, opaque envelopes); or unclear risk of bias (when the method was not clearly stated). We excluded studies that did not conceal allocation and were therefore at a high risk of bias (eg, open list).

3. Blinding of participants and personnel (checking for possible performance bias). We planned to assess any methods used to blind the participants and personnel from knowledge of which intervention a participant received. We planned to assess the methods as: low risk of bias (study stated that the participants and personnel involved were blinded to treatment groups); unclear risk of bias (study did not state either way as to whether participants and personnel were blinded to treatment groups); or high risk of bias (participants or personnel were not blinded) (as stated in Types of studies, we planned to still include trials, with or without blinding, and participant or observer reported outcomes).

4. Blinding of outcome assessment (checking for possible detection bias). We planned to assess any methods used to blind the outcome assessors from knowledge of which intervention a participant received. We planned to assess the methods as: low risk of bias (eg study stated that it was singleblinded and described the method used to achieve blinding of the outcome assessor); unclear risk of bias (study stated that outcome assessors were blinded but did not provide an adequate description of how it was achieved); or high risk of bias (outcome assessors were not blinded) (as stated in Types of studies, we planned to still include trials, with or without blinding, and participant or observer reported outcomes).

5. Incomplete outcome data (checking for possible attrition bias due to the amount, nature, and handling of incomplete outcome data). We planned to assess the methods used to deal with incomplete data as: low risk of bias (ie fewer than $10 \%$ of participants did not complete the study or used 'baseline observation carried forward' (BOCF) analysis, or both); unclear risk of bias (used 'last observation carried forward' (LOCF) analysis); or high risk of bias (used 'completer' analysis).

6. Selective reporting (checking for possible reporting bias). We planned to assess the methods used to report the outcomes of the study as: low risk of bias (if all planned outcomes in the protocol or methods were also reported in the results); unclear risk of bias (if there was not a clear distinction between planned outcomes and reported outcomes); high risk of bias (if some planned outcomes from the protocol or methods were clearly left out of the results).

7. Size of study (checking for possible biases confounded by small size). We planned to assess studies as being at low risk of bias (200 participants or more per treatment arm); unclear risk of bias (50 to 199 participants per treatment arm); or high risk of bias (fewer than 50 participants per treatment arm).

8. Other bias. We planned to assess studies for any additional sources of bias as low, unclear or high, and provide rationale.

\section{Measures of treatment effect}

Where dichotomous data were available, we planned to calculate a risk ratio (RR) with $95 \%$ confidence intervals (Cls) and metaanalyse the data as appropriate. We planned to calculate numbers needed to treat for an additional beneficial outcome (NNTBs) where appropriate (McQuay 1998); for unwanted effects the NNTB becomes the number needed to treat for an additional harmful outcome (NNTH) and is calculated in the same manner. Where continuous data were reported, we planned to use appropriate methods to combine these data in the meta-analysis.

\section{Unit of analysis issues}

We planned to accept randomisation to the individual participant only. We planned to split the control treatment arm between active treatment arms in a single study if the active treatment arms were not combined for analysis. We only accepted studies with a minimum 10 participants per treatment arm.

\section{Dealing with missing data}

We planned to use intention-to-treat (ITT) analysis where the ITT population consisted of participants who were randomised, took at least one dose of the assigned study medication, and provided at least one post-baseline assessment. We planned to assign missing participants zero improvement wherever possible.

\section{Assessment of heterogeneity}

We planned to identify and measure heterogeneity as recommended in chapter 9 of the Cochrane Handbook for Systematic Reviews of Interventions (Higgins 2011). We planned to deal with clinical heterogeneity by combining studies that examined similar conditions. We planned to undertake and present a meta-analysis only if participants, interventions, comparisons, and outcomes were judged to be sufficiently similar to ensure an answer that is clinically meaningful. We planned to assess statistical heterogeneity visually (L'Abbé 1987), and with the use of the $I^{2}$ statistic. When $I^{2}$ was greater than $50 \%$, we planned to consider the possible reasons.

\section{Assessment of reporting biases}

We planned to assess the risk of reporting bias, as recommended in chapter 8 of the Cochrane Handbook for Systematic Reviews of Interventions (Higgins 2011). 
The aim of this review was to use dichotomous outcomes of known utility and value to patients (Hoffman 2010; Moore 2010b; Moore 2010c; Moore 2010d; Moore 2013a). The review did not depend on what the authors of the original studies chose to report or not, although clearly difficulties were predicted to arise in studies that failed to report any dichotomous results. We planned to extract and use continuous data, which may reflect efficacy and utility poorly, and may have been useful for illustrative purposes only.

We planned to assess publication bias using a method designed to detect the amount of unpublished data with a null effect required to make any result clinically irrelevant (usually taken to mean a number needed to treat (NNT) of 10 or higher; Moore 2008).

\section{Data synthesis}

We planned to use a fixed-effect model for meta-analysis. We planned to use a random-effects model for meta-analysis if there was significant clinical heterogeneity and it was considered appropriate to combine studies. We planned to conduct our analysis using the primary outcomes of pain and adverse events, and we planned to calculate the NNTHs for adverse events. We planned to use the Cochrane software program Review Manager 5.3 (Review Manager 2014).

\section{Quality of evidence}

To analyse data, two review authors planned to independently rate the quality of each outcome. We planned to use the GRADE approach to assess the quality of the body of the evidence related to each of the key outcomes, and report our judgement on the quality of the evidence in the 'Summary of findings' table (chapter 12, Higgins 2011; Appendix 6).

In addition, there may have been circumstances where the overall rating for a particular outcome needed to be adjusted as recommended by GRADE guidelines (Guyatt 2013a). For example, if there were so few data that the results were highly susceptible to the random play of chance, or if studies used LOCF imputation in circumstances where there were substantial differences in adverse event withdrawals, one would have no confidence in the result, and would need to downgrade the quality of the evidence by three levels, to very low quality. In circumstances where there were no data reported for an outcome, we planned to report that there was no evidence to support or refute (Guyatt 2013b).

\section{'Summary of findings' table}

We planned to include a 'Summary of findings' table as set out in the Cochrane PaPaS Review Group's author guide (AUREF 2012), and recommended in theCochrane Handbook for Systematic Reviews of Interventions, chapter 4.6.6 (Higgins 2011). We planned to justify and document all assessments of the quality of the body of evidence.

In an attempt to interpret reliability of the findings for this systematic review, we planned to assess the summarised data using the GRADE guidelines (Appendix 6) to rate the quality of evidence (Guyatt 2011) of each of the key outcomes listed in Types of outcome measures (chapter 12, Higgins 2011), as appropriate. Using the explicit criteria against: study design, risk of bias, imprecision, inconsistency, indirectness, and magnitude of effect, we planned to summarise the evidence in an informative, transparent and succinct 'Summary of findings' table or 'Evidence profile' table (Guyatt 2011).

\section{Subgroup analysis and investigation of heterogeneity}

We planned to perform subgroup analyses where a minimum number of data were available (at least 200 participants per treatment arm). We planned to analyse according to age group; type of drug; geographical location or country; type of control group; baseline measures; frequency, dose and duration of drugs; nature of drug.

We planned to investigate whether the results of subgroups were significantly different by inspecting the overlap of confidence intervals and performing the test for subgroup differences available in RevMan.

\section{Sensitivity analysis}

We did not plan to carry out any sensitivity analysis because the evidence base was known to be too small to enable reliable analysis; we did not plan to pool results from cancer pain of different origins in the primary analyses. We planned to examine details of dose escalation schedules in the unlikely situation that this could provide some basis for a sensitivity analysis.

\section{RES U LT S}

\section{Description of studies}

Results of the search

A PRISMA flow diagram of the search results is shown in Figure 1. 
Figure 1. Study flow diagram.

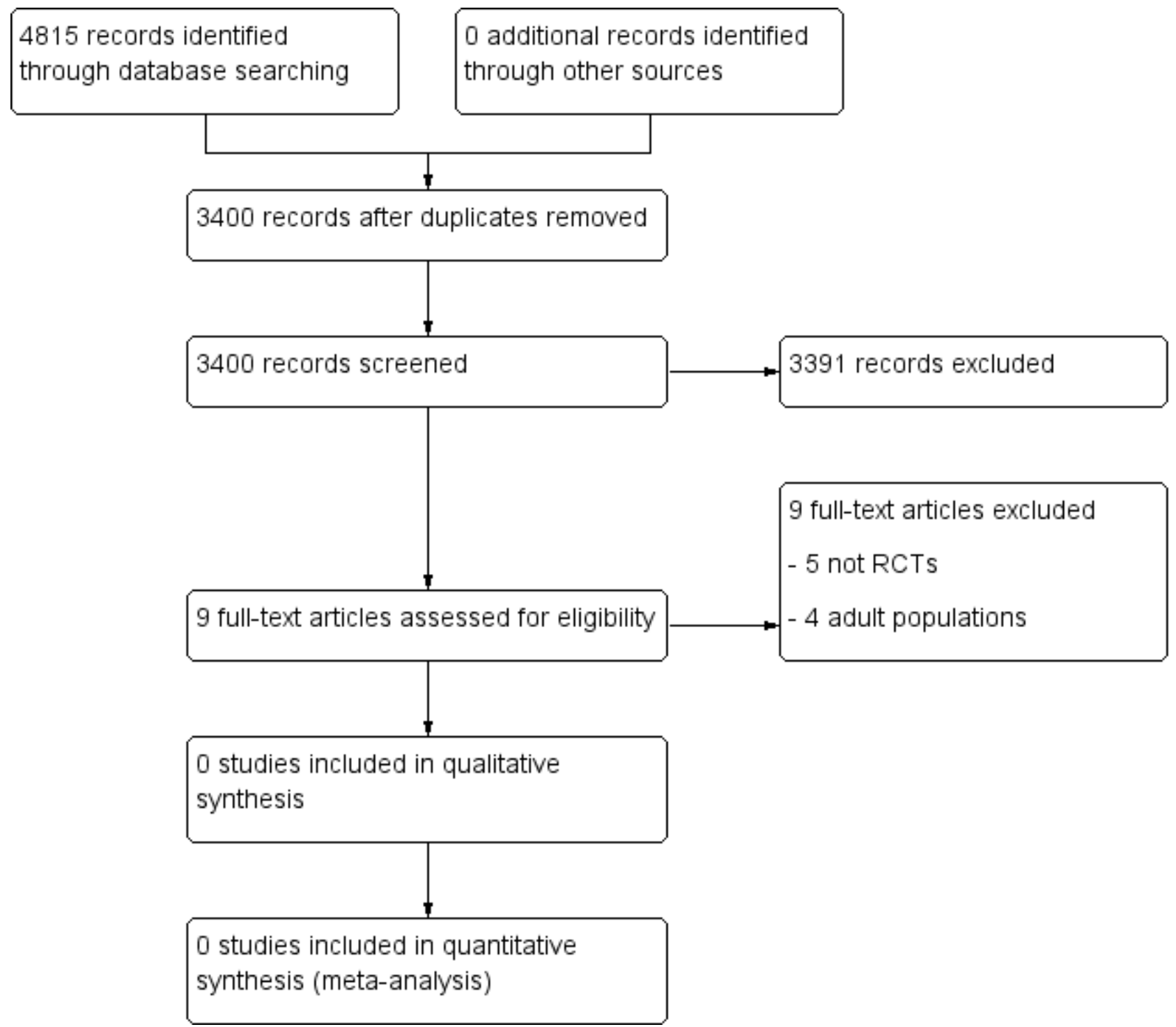

Searches of the three main databases revealed 4815 records of titles and abstracts, of which we removed 1417 duplicates. We also searched clinicaltrials.gov and app.who.int/trialsearch/ and found no additional eligible studies.

We screened the remaining 3400 titles and abstracts for eligibility, of which we removed 3391 as ineligible studies.

Of the remaining nine studies we retrieved the full text articles, and excluded all nine. No ongoing studies were identified. No studies fulfilled the eligibility criteria, nor were any eligible to be entered into a quantitative analysis.

\section{Included studies}

No studies met our inclusion criteria for this review.

\section{Excluded studies}

See Characteristics of excluded studies.

We excluded nine studies in this review.
Upon reading the full texts, we discovered three studies were in adult populations (Cappelaere 1971; Harris 2003; Toscani 1994), and one investigated participants whose ages ranged from 5 to 69 years; however, subunit data were not available (Mercandante 1999). Five studies were not RCTs (Bottner 2001; Gross 2003; Lauretti 1998; Sittl 1991; Zhen 2007).

\section{Risk of bias in included studies}

Because no studies were eligible for inclusion we could not assess the efficacy of NSAIDs for treating cancer-related pain in children and adolescents.

\section{Effects of interventions}

No studies were eligible for inclusion in this review, therefore, we were not able to comment on the efficacy or harm from the use of NSAIDs to treat cancer-related pain in children and adolescents.

Due to the lack of evidence in this field, we were unable to judge the quality of evidence. There are no data and therefore no evidence to 
support or refute the use of NSAIDs for treating cancer-related pain in children and adolescents.

\section{DISCUSSION}

\section{Summary of main results}

We found no randomised controlled trials (RCTs) for inclusion in this review. There are no data from RCTs to inform assessment of the effectiveness of NSAIDs in treating cancer-related pain in children and adolescents. NSAIDs are used in adults alongside other analgesics as they are thought to be useful for bone pain. There is currently no high quality evidence for their use (Derry 2017).

\section{Overall completeness and applicability of evidence}

As no RCTs could be identified we were unable to comment about efficacy or harm from the use of NSAIDs to treat cancer-related pain in children and adolescents. Similarly, we could not comment on our remaining secondary outcomes: carer global impression of change; requirement for rescue analgesia; sleep duration and quality; acceptability of treatment; physical functioning; and quality of life.

\section{The suite of reviews}

This review is part of a suite of reviews on pharmacological interventions for chronic pain and cancer-related pain in children and adolescents (Appendix 1). Taking a broader view on this suite of reviews, some pharmacotherapies (investigated in our other reviews) are likely to provide more data than others. Thus, the results were as expected considering that RCTs in children are known to be limited. The results have the potential to assist to inform policy making decisions for funding future clinical trials into NSAID treatment of child and adolescent pain, therefore, any results (large or small) are important to capture a snapshot of the current evidence for NSAIDs.

\section{Quality of the evidence}

Due to the lack of evidence in this field, we were unable to judge the quality of evidence. There is no evidence to support or refute the use of NSAIDs for treating cancer-related pain in children and adolescents. We were unable to find any published RCTs to support or refute the use of NSAIDs to treat cancer-related pain in children and adolescents. We were unable to examine any adverse effects.

This review may represent a case of absence of evidence rather than evidence of absence. While it may be true that the absence of evidence may reflect that NSAIDs per se are inadequately effective and their use as monotherapy analgesics is more likely to cause harm than benefit, the opposite may also pertain as data are lacking. It is difficult to conduct long-term RCTs in children with cancer-related pain, and few observational/clinical data have been published.

\section{Potential biases in the review process}

We carried out extensive searches of major databases using broad search criteria, and also searched two large clinical trial registries. We think it is unlikely that we have missed relevant studies.

\section{Agreements and disagreements with other studies or reviews}

We were not able to identify any published systematic reviews on this topic.

\section{AUTHORS' CONCLUSIONS}

\section{Implications for practice}

\section{General}

We identified no randomised controlled trials (RCTs), to support or refute the use of NSAIDs to treat cancer-related pain in children and adolescents.

This is disappointing as children and adolescents have specific needs for analgesia. Extrapolating from adult data may be possible but could compromise effectiveness and safety.

Despite the lack of evidence of long-term effectiveness and safety, we know that clinicians prescribe NSAIDs to children and adolescents when medically necessary, based on extrapolation from adult guidelines (e.g. CDC Guidelines, Dowell 2016), when perceived benefits in conjunction with other multi-modalities improve a child's care. The evidence for the use of NSAIDs for cancer pain in adults is low quality (Derry 2017)

In current practice, despite the lack of high quality evidence, NSAIDs are given to young children and adolescents based on clinical knowledge and experience.

\section{For children with cancer-related pain}

Children and adolescents experiencing cancer pain need to be adequately treated, despite there being little good evidence around the use of NSAIDs for treating cancer-related pain. At present, treatment is based on clinical experience, extrapolation from evidence and experience in adults, and advice from respected authorities. No judgment can be made about adverse events or withdrawals.

\section{For clinicians}

Children and adolescents experiencing cancer pain need to be adequately treated, despite there being little good evidence around the use of NSAIDs for treating cancer-related pain. At present, treatment is based on clinical experience, extrapolation from evidence and experience in adults, and advice from respected authorities. No judgment can be made about adverse events or withdrawals.

\section{For policy makers}

Children and adolescents experiencing cancer pain need to be adequately treated, despite there being little good evidence around the use of NSAIDs for treating cancer-related pain. At present, treatment is based on clinical experience, extrapolation from evidence and experience in adults, and advice from respected authorities. No judgment can be made about adverse events or withdrawals.

\section{For funders}

Children and adolescents experiencing cancer pain need to be adequately treated, despite there being little good evidence around the use of NSAIDs for treating cancer-related pain. At present, 
treatment is based on clinical experience, extrapolation from evidence and experience in adults, and advice from respected authorities. No judgment can be made about adverse events or withdrawals.

\section{Implications for research}

\section{General}

The heterogenous nature of pain in children needs to be recognised and presents challenges in designing research studies. In addition, children experience fewer solid tumours and so generally do not experience pain from that source.

Overall, there appears to be a gap between what is done in practice and what is investigated in prospective clinical trials for treating children's and adolescents' pain with NSAIDs.

The lack of evidence highlighted in this review implies there is a need to fund and support suitable research for the treatment of cancer-related pain in children and adolescents using NSAIDs.

\section{Design}

Several methodological issues stand out.

The first is the use of outcomes of value to children with cancer pain. Existing trials are designed more for purposes of registration and marketing than informing and improving clinical practice, often because the outcomes chosen are average pain scores, or statistical differences, and rarely how many children achieve satisfactory pain relief. In the situation where initial pain is mild or moderate, some consideration needs to be given to what constitutes a satisfactory outcome. The situation is somewhat different to that of strong opioids in cancer pain that are used for moderate to severe pain.

The second is the time taken to achieve good pain relief. We have no information about what constitutes a reasonable time to achieve a satisfactory result. Initially this may best be approached with a Delphi methodology involving children and their carers.

The third is design. Studies with cross-over design often have significant attrition. Parallel group designs may be preferable.
The fourth is size. The studies need to be suitably powered to ensure adequate data after the effect of attrition due to various causes. Much larger studies of several hundred participants or more are needed. This may require a multicentre approach.

There are some other design issues that might be addressed. Most important might well be a clear decision concerning the gold-standard treatment comparator. Placebo-controlled studies in cancer pain are unlikely to be ethically feasible. It may be that low dose oral morphine is a suitable comparator, as a suggested alternative treatment for mild to moderate pain.

An alternative approach might be to design large registry studies. This could provide an opportunity to foster collaboration among paediatric clinicians and researchers to create an evidence base.

\section{Measurement (endpoints)}

Trials need to consider additional endpoints of no worse than mild pain as well as the standard approaches to pain assessment.

\section{Other}

Prospective randomised trials is the obvious design of choice, but other pragmatic designs may be worth considering. Studies could incorporate initial randomisation, but a pragmatic design to provide immediately-relevant information on effectiveness and costs. Such designs in pain conditions have been published (Moore 2010e).

\section{ACKNOWLEDGEMENTS}

We acknowledge the contribution of Phil Wiffen to the template protocol.

We thank Gillian Dickson, EAH Loeffen and Andrew Moore for peer reviewing.

Cochrane Review Group funding acknowledgement: the National Institute for Health Research (NIHR) is the largest single funder of the Cochrane Pain, Palliative and Supportive Care Review Group (PaPaS). Disclaimer: the views and opinions expressed herein are those of the authors and do not necessarily reflect those of the NIHR, National Health Service (NHS), or the Department of Health. 


\section{R E F E R E N C E S}

\section{References to studies excluded from this review}

Bottner 2001 \{published data only\}

Bottner F, Roedl R, Wortler K, Grethen C, Winkelmann W, Lindner N. Cyclooxygenase-2 inhibitor for pain management in osteoid osteoma. Clinical Orthopaedics and Related Research 2001;393:258-63.

\section{Cappelaere 1971 \{published data only\}}

Cappelaere P, Adenis L, Driessens J. Value of injectable aspirin in cancerology. Lille Medical 1971;17(3):566-71.

Gross 2003 \{published data only\}

Gross M, Dano I, Hocwald E, Eliashar R. Osteoid osteoma of the frontal bone. Annals of Otology, Rhinology, and Laryngology 2003;112(6):567-8

\section{Harris 2003 \{published data only\}}

Harris JT, Suresh Kumar K, Rajagopal MR. Intravenous morphine for rapid control of severe cancer pain. Palliative Medicine 2003;17(3):248-56

\section{Lauretti 1998 \{published data only\}}

Lauretti GR, Reis MP, Mattos Al, Gomes JM, Oliveria AP, Pereira NL. Epidural nonsteroidal antiinflammatory drugs for cancer pain. Anesthesia and Analgesia 1998;86(1):117-8.

\section{Mercandante 1999 \{published data only\}}

Mercadante S. Pain treatment and outcomes for patients with advanced cancer who receive follow-up care at home. Cancer 1999;85(8):1849-58.

\section{Sittl 1991 \{published data only\}}

Sittl R, Richter R. Cancer pain therapy in children and adolescents using morphine. Der Anaesthesist 1991;40(2):96-9.

\section{Toscani 1994 \{published data only\}}

Toscani F, Piva L, Corli O, Gallucci M, Speranza R, Tamburini M, et al. Ketorolac versus diclofenac sodium in cancer pain. Arzneimittel-Forschung 1994;44(4):550-4.

\section{Zhen 2007 \{published data only\}}

Zhen ZJ, Sun XF, Xia Y, Ling JY, Zheng L, Luo WB, et al. Feasibility to treat pediatric cancer pain with analgesics for adults and their efficacy. Chinese Journal of Cancer 2007;26(8):866-9.

\section{Additional references}

\section{ACS 2015}

American Cancer Society. Cancer in children. www.cancer.org/ cancer/cancerinchildren/detailedguide/cancer-in-childrentypes-of-childhood-cancers (accessed 16 July 2016).

\section{AMA 2013}

American Medical Association. Paediatric pain management. https://www.ama-assn.org/ (accessed 25 January 2016).

\section{AUREF 2012}

Cochrane Pain, Palliative and Supportive Care Group. PaPaS author and referee guidance. papas.cochrane.org/papasdocuments (accessed 16 July 2016).

\section{Blanca-López 2015}

Blanca-López N, Cornejo-García JA, Plaza-Serón MC, Doña I, Torres-Jaén MJ, Canto G, et al. Hypersensitivity to nonsteroidal anti-inflammatory drugs in children and adolescents: crossintolerance reactions. Journal of Investigational Allergology \& Clinical Immunology 2015;25(4):259-69.

\section{BNF 2016}

Joint Formulary Committee. British National Formulary. London (UK): BMJ Group and Pharmaceutical Press, 2016.

\section{Caes 2016}

Caes L, Boemer KE, Chambers CT, Campbell-Yeo M, Stinson J, Birnie KA, et al. A comprehensive categorical and bibliometric analysis of published research articles on pediatric pain from 1975 to 2010. Pain 2016;157(2):302-13. [DOI: 10.1097/ j.pain.0000000000000403]

\section{Calvo 2012}

Calvo M, Dawes JM, Bennett DL. The role of the immune system in the generation of neuropathic pain. Lancet Neurology 2012;11(7):629-42. [DOI: 10.1016/S1474-4422(12)70134-5]

\section{Cooper 2017a}

Cooper TE, Fisher E, Gray A, Krane E, Sethna NF, van Tilburg M, et al. Opioids for chronic non-cancer pain in children and adolescents. Cochrane Database of Systematic Reviews 2017, Issue 7. [DOI: 10.1002/14651858.CD012538.pub2]

\section{Cooper 2017b}

Cooper TE, Heathcote L, Clinch J, Gold J, Howard R, Lord S, et al. Antidepressants for chronic non-cancer pain in children and adolescents. Cochrane Database of Systematic Reviews 2017, Issue 8. [DOI: 10.1002/14651858.CD012535.pub2]

\section{Cooper 2017c}

Cooper TE, Fisher E, Anderson B, Wilkinson N, Williams G, Eccleston C. Paracetamol (acetaminophen) for chronic non-cancer pain in children and adolescents. Cochrane Database of Systematic Reviews 2017, Issue 8. [DOI: 10.1002/14651858.CD012539.pub2]

\section{Derry 2017}

Derry S, Wiffen PJ, Moore RA, McNicol ED, Bell RF, Carr DB, et al. Oral nonsteroidal anti-inflammatory drugs (NSAIDs) for cancer pain in adults. Cochrane Database of Systematic Reviews 2017, Issue 4. [DOI: 10.1002/14651858.CD012638]

\section{Dowell 2016}

Dowell D, Haegerich TM, Chou R. CDC guideline for prescribing opioids for chronic pain - United States. JAMA 2016;315(15):1624-45. 


\section{Dworkin 2008}

Dworkin RH, Turk DC, Wyrwich KW, Beaton D, Cleeland CS, Farrar JT, et al. Interpreting the clinical importance of treatment outcomes in chronic pain clinical trials: IMMPACT recommendations. Journal of Pain 2008;9(2):105-21. [DOI: 10.1016/j.jpain.2007.09.005]

\section{Eccleston 2003}

Eccleston C, Malleson PM. Management of chronic pain in children and adolescents. We need to address the embarrassing lack of data for this common problem. BMJ 2003;326(7404):1408-9.

\section{Eccleston 2017}

Eccleston C, Cooper TE, Fisher E, Anderson B, Wilkinson N. Non-steroidal anti-inflammatory drugs (NSAIDs) for chronic non-cancer pain in children and adolescents. Cochrane Database of Systematic Reviews 2017, Issue 8. [DOI: 10.1002/14651858.CD012537.pub2]

\section{Frankish 2003}

Frankish H. 15 million new cancer cases per year by 2020, says WHO. Lancet 2003;361(9365):1278.

\section{Guyatt 2008}

Guyatt GH, Oxman AD, Vist GE, Kunz R, Falck-Ytter Y, AlonsoCoello $P$, et al. GRADE: an emerging consensus on rating quality of evidence and strength of recommendations. $B M J$ 2008;336(7650):924-6. [DOI: 10.1136/bmj.39489.470347.AD]

\section{Guyatt 2011}

Guyatt G, Oxman AD, Akl EA, Kunz R, Vist G, Brozek J, et al. GRADE Guidelines: 1. Introduction-GRADE evidence profiles and summary of findings tables. Journal of Clinical Epidemiology 2011;64(4):383-94. [DOI: 10.1016/j.jclinepi.2010.04.026]

\section{Guyatt 2013a}

Guyatt G, Oxman AD, Sultan S, Brozek J, Glasziou P, AlonsoCoelle $P$, et al. Making an overall rating of the confidence in effect estimates for a single outcome and for all outcomes. Journal of Clinical Epidemiology 2013;66(2):151-7. [DOI: 10.1016/ j.jclinepi.2012.01.006]

\section{Guyatt 2013b}

Guyatt GH, Oxman AD, Santesso N, Helfand M, Vist G, Kunz R, et al. GRADE guidelines: 12 . Preparing summary of findings tables-binary outcomes. Journal of Clinical Epidemiology 2013;66(2):158-72. [DOI: 10.1016/j.jclinepi.2012.01.012]

\section{Hasnie 2007}

Hasnie FS, Breuer J, Parker S, Wallace V, Blackbeard J, Lever I, et al. Further characterization of a rat model of varicella zoster virus-associated pain: Relationship between mechanical hypersensitivity and anxiety-related behavior, and the influence of analgesic drugs. Neuroscience 2007;144(4):1495-508. [DOI: 10.1016/j.neuroscience.2006.11.029]

\section{Higgins 2011}

Higgins JPT, Green S (editors). Cochrane Handbook for Systematic Reviews of Interventions Version 5.1.0 (updated
March 2011). The Cochrane Collaboration, 2011. Available from handbook.cochrane.org.

\section{Hoffman 2010}

Hoffman DL, Sadosky A, Dukes EM, Alvir J. How do changes in pain severity levels correspond to changes in health status and function in patients with painful diabetic peripheral neuropathy?. Pain 2010;149(2):194-201. [DOI: 10.1016/ j.pain.2009.09.017]

\section{IARC 2008}

International Association on the Research of Cancer. Global cancer facts \& figures. www.cancer.org/acs/groups/ content/@epidemiologysurveilance/documents/document/ acspc-027766.pdf (accessed 7 March 2016).

\section{Kaatsch 2010}

Kaatsch P. Epidemiology of childhood cancer. Cancer Treatment Reviews 2010;36(4):277-85. [DOI: 10.1016/ctrv.2010.02.003]

\section{Kawakami 2002}

Kawakami M, Matsumoto T, Hashizume H, Kuribayashi K, Tamaki T. Epidural injection of cyclooxygenase-2 inhibitor attenuates pain-related behavior following application of nucleus pulposus to the nerve root in the rat. Journal of Orthopaedic Research 2002;20(2):376-81. [DOI: 10.1016/ S0736-0266(01)00114-0]

\section{L'Abbé 1987}

L'Abbé KA, Detsky AS, O'Rourke K. Meta-analysis in clinical research. Annals of Internal Medicine 1987;107(2):224-33.

\section{Lesko 1995}

Lesko SM, Mitchell AA. An assessment of the safety of pediatric ibuprofen. Journal of the American Medical Association 1995;273(12):929-33.

\section{Lesko 1997}

Lesko SM, Mitchell AA. Renal function after short-term ibuprofen use in infants and children. Pediatrics 1997;100(6):954-7.

\section{Lesko 1999}

Lesko SM, Mitchel AA. The safety of acetaminophen and ibuprofen among children younger than two years old. Pediatrics 1999;104(4):e39.

\section{Ljungman 1996}

Ljungman G, Kreuger A, Gordh T, Berg T, Sörensen S, Rawal N. Treatment of pain in pediatric oncology: a Swedish nationwide surgery. Pain 1996;68(2-3):385-94.

\section{McQuay 1998}

McQuay H, Moore R. An Evidence-based Resource for Pain Relief. Oxford (UK): Oxford University Press, 1998.

\section{Misurac 2013}

Misurac JM, Knoderer CA, Leiser JD, Nailsecu C, Wilson AC, Andreoli SP. Nonsteroidal anti-inflammatory drugs are an important cause of acute kidney injury in children. Journal of Pediatrics 2013;162(6):1153-9. [DOI: 10.1016/ j.jpeds.2012.11.069] 


\section{Moher 2009}

Moher D, Liberati A, Tetzlaff J, Altman DG, the PRISMA Group. Preferred reporting items for systematic reviews and meta-analyses: the PRISMA statement. PLoS Medicine 2009;6(7):e1000097.

\section{Moore 2008}

Moore RA, Barden J, Derry S, McQuay HJ. Managing potential publication bias. In: McQuay HJ, Kalso E, Moore RA editor(s). Systematic Reviews in Pain Research: Methodology Refined. Seattle (WA): IASP Press, 2008:15-24. [ISBN: 978-0-931092-69-5]

\section{Moore 2009}

Moore RA, Straube S, Wiffen PJ, Derry S, McQuay HJ. Pregabalin for acute and chronic pain in adults. Cochrane Database of Systematic Reviews 2009, Issue 3. [DOI: 10.1002/14651858.CD007076.pub2]

\section{Moore 2010a}

Moore RA, Eccleston C, Derry S, Wiffen P, Bell RF, Straube S, et al. "Evidence" in chronic pain - establishing best practice in the reporting of systematic reviews. Pain 2010;150(3):386-9. [DOI: 10.1016/j.pain.2010.05.011]

\section{Moore 2010b}

Moore RA, Straube S, Paine J, Phillips CJ, Derry S, McQuay HJ. Fibromyalgia: moderate and substantial pain intensity reduction predicts improvement in other outcomes and substantial quality of life gain. Pain 2010;149(2):360-4.

\section{Moore 2010c}

Moore RA, Moore OA, Derry S, Peloso PM, Gammaitoni AR, Wang $\mathrm{H}$. Responder analysis for pain relief and numbers needed to treat in a meta-analysis of etoricoxib osteoarthritis trials: bridging a gap between clinical trials and clinical practice. Annals of the Rheumatic Diseases 2010;69(2):374-9. [DOI: 10.1136/ard.2009.107805]

\section{Moore 2010d}

Moore RA, Smugar SS, Wang H, Peloso PM, Gammaitoni A. Numbers-needed-to-treat analyses - do timing, dropouts, and outcome matter? Pooled analysis of two randomized, placebocontrolled chronic low back pain trials. Pain 2010;151(3):592-7. [DOI: 10.1016/j.pain.2010.07.2013]

\section{Moore 2010e}

Moore RA, Derry S, McQuay HJ, Straube S, Aldington D, Wiffen P, et al. ACTINPAIN writing group of the IASP Special Interest Group (SIG) on Systematic Reviews in Pain Relief. Clinical effectiveness: an approach to clinical trial design more relevant to clinical practice, acknowledging the importance of individual differences. Pain 2010;149(2):173-6. [PUBMED: 19748185]

\section{Moore 2011a}

Moore RA, Straube S, Paine J, Derry S, McQuay HJ. Minimum efficacy criteria for comparisons between treatments using individual patient meta-analysis of acute pain trials: examples of etoricoxib, paracetamol, ibuprofen, and ibuprofen/ paracetamol combinations after third molar extraction. Pain 2011;152(5):982-9. [DOI: 10.1016/j.pain.2010.11.030]

\section{Moore 2011b}

Moore RA, Mhuircheartaigh RJ, Derry S, McQuay HJ. Mean analgesic consumption is inappropriate for testing analgesic efficacy in post-operative pain: analysis and alternative suggestion. European Journal of Anaesthesiology 2011;28(6):427-32. [DOI: 10.1097/EJA.0b013e328343c569]

\section{Moore 2012}

Moore RA, Straube S, Eccleston C, Derry S, Aldington D, Wiffen P, et al. Estimate at your peril: imputation methods for patient withdrawal can bias efficacy outcomes in chronic pain trials using responder analyses. Pain 2012;153(2):265-8. [DOI: 10.1016/j.pain.2011.10.004]

\section{Moore 2013a}

Moore RA, Straube S, Aldington D. Pain measures and cut-offs - 'no worse than mild pain' as a simple, universal outcome. Anaesthesia 2013;68(4):400-12. [DOI: 10.1111/anae.12148]

\section{Moore 2013b}

Moore A, Derry S, Eccleston C, Kalso E. Expect analgesic failure; pursue analgesic success. BMJ 2013;346:f2690. [DOI: 10.1136/ bmj.f2690]

\section{Moore 2014a}

Moore RA, Derry S, Taylor RS, Straube S, Phillips CJ. The costs and consequences of adequately managed chronic non-cancer pain and chronic neuropathic pain. Pain Practice 2014;14(1):79-94.

\section{Moore 2014b}

Moore RA, Cai N, Skljarevski V, Tölle TR. Duloxetine use in chronic painful conditions - individual patient data responder analysis. European Journal of Pain 2014;18(1):67-75. [DOI: 10.1002/j.1532-2149.2013.00341.x]

\section{NICE 2015}

National Institute of Health and Care Excellence (NICE). Guidance - sickle cell acute painful episode. https:// www.nice.org.uk/guidance/cg143/evidence/full-guidelinepdf-186634333 (accessed 7 September 2015).

\section{O'Brien 2010}

O'Brien EM, Staud RM, Hassinger AD, McCulloch RC, Craggs JG, Atchinson JW, et al. Patient-centered perspective on treatment outcomes in chronic pain. Pain Medicine 2010;11(1):6-15. [DOI: 10.1111/j.1526-4637.2009.00685.x]

\section{PedIMMPACT 2008}

McGrath PJ, Walco GA, Turk DC, Dworking RH, Brown MT, Davidson $\mathrm{K}$, et al. Core outcome domains and measures for pediatric acute and chronic/recurrent pain clinical trials: PedIMMPACT. Journal of Pain 2008;9(9):771-83.

\section{Review Manager 2014 [Computer program]}

Nordic Cochrane Centre, The Cochrane Collaboration. Review Manager 5 (RevMan 5). Version 5.3. Copenhagen: Nordic Cochrane Centre, The Cochrane Collaboration, 2014. 


\section{Ripamonti 2008}

Ripamonti C, Bandieri E. Pain therapy. Journal of Hematology \& Oncology 2008;70(2):145-59. [DOI: 10.1016/ j.critrevonc.2008.12.005]

\section{Stinson 2006}

Stinson JN, Kavanagh T, Yamada J, Gill N, Stevens B. Systematic review of the psychometric properties, interpretability and feasibility of self-report pain intensity measures for use in clinical trials in children and adolescents. Pain 2006;125(1-2):143-57. [DOI: 10.1016/j.pain.2006.05.006]

\section{Straube 2008}

Straube S, Derry S, McQuay HJ, Moore RA. Enriched enrolment: definition and effects of enrichment and dose in trials of pregabalin and gabapentin in neuropathic pain. A systematic review. British Journal of Clinical Pharmacology 2008;66(2):266-75. [DOI: 10.1111/j.1365-2125.2008.03200.x]

\section{Straube 2010}

Straube S, Derry S, Moore RA, Paine J, McQuay HJ. Pregabalin in fibromyalgia - responder analysis from individual patient data. BMC Musculoskeletal Disorders 2010;11:150. [DOI: 10.1186/1471-2474-11-150]

\section{Sultan 2008}

Sultan A, Gaskell H, Derry S, Moore RA. Duloxetine for painful diabetic neuropathy and fibromyalgia pain: systematic review of randomised trials. BMC Neurology 2008;8:29. [DOI: 10.1186/1471-2377-8-29]

\section{Tanko 2009}

Tanko NM, Echejoh GO, Manasseh NA, Mandong MB, Uba AF. Paediatric solid tumours in Nigerian children: a changing pattern. African Journal of Paediatric Surgery 2009;6(1):7-10.

\section{United Nations 2017}

United Nations. World Population Prospects 2017 - Population Indicators. esa.un.org/unpd/wpp/Download/Standard/ Population (accessed prior to 3 July 2017).

\section{Vo 2009}

Vo T, Rice ASC, Dworkin RH. Non-steroidal anti-inflammatory drugs for neuropathic pain: How do we explain continued widespread use?. Pain 2009;143(3):169-71. [DOI: 10.1016/

j.pain.2009.03.013]

\section{Von Baeyer 2007}

Von Baeyer CL, Spagrud LJ. Systematic review of observational (behavioural) measures of pain for children and adolescents aged 3 to 18 years. Pain 2007;127(1-2):140-50. [DOI: 10.1016/ j.pain.2006.08.014]

\section{WHO 1998}

World Health Organization. Cancer pain relief and palliative care in children. apps.who.int/iris/ bitstream/10665/42001/1/9241545127.pdf (accessed prior to 3 July 2017).

\section{WHO 2011}

World Health Organization. Cancer Fact Sheet N²97. www.who.int/mediacentre/factsheets/fs297/en/ (accessed 06 March 2017).

\section{WHO 2012}

World Health Organization. WHO guidelines on the pharmacological treatment of persisting pain in children with medical illnesses. apps.who.int/iris/ bitstream/10665/44540/1/9789241548120_Guidelines.pdf (accessed prior to 3 July 2017). [ISBN: 978924154812 0]

\section{Wiffen 2017a}

Wiffen PJ, Cooper TE, Anderson AK, Gray A, Grégoire MC, Ljungman $\mathrm{G}$, et al. Opioids for cancer-related pain in children and adolescents. Cochrane Database of Systematic Reviews 2017, Issue 7. [DOI: 10.1002/14651858.CD012564.pub2]

\section{Wiffen 2017b}

Wiffen PJ, Cooper TE, Heathcote L, Clinch J, Howard R, Krane E, et al. Antiepileptic drugs for chronic non-cancer pain in children and adolescents. Cochrane Database of Systematic Reviews 2017, Issue 8. [DOI: 10.1002/14651858.CD012536.pub2]

\section{World Bank 2016}

The World Bank. Data - population ages 0-14 (\% of total). data.worldbank.org/indicator/SP.POP.0014.TO.ZS (accessed 29 February 2016).

\section{CHARACTERISTICS OF STUDIES}

Characteristics of excluded studies [ordered by study ID]

\begin{tabular}{ll}
\hline Study & Reason for exclusion \\
\hline Bottner 2001 & Allocation: not RCT. \\
\hline Cappelaere 1971 & Population: adults. \\
\hline Gross 2003 & Intervention: case study, not RCT. \\
\hline Harris 2003 & Population: adults. \\
\hline
\end{tabular}




\section{Study Reason for exclusion}

Lauretti $1998 \quad$ Intervention: case study, not RCT.

\begin{tabular}{ll}
\hline Mercandante 1999 & Population: Age range 5 to 69 years. Attempted contact for subunit data. \\
\hline Sittl 1991 & Allocation/study design: not RCT. \\
\hline Toscani 1994 & Population: adults. \\
\hline Zhen 2007 & Allocation/study design: not an RCT. \\
\hline
\end{tabular}

\section{APPENDICES}

\section{Appendix 1. Meeting for NIHR Programme Grant agenda on pain in children}

\section{Date}

Monday 1st June 2015

\section{Location}

International Association of the Study of Pain (IASP) Conference, Seattle, USA

\section{Delegates}

Allen Finlay, Anna Erskine, Boris Zernikow, Chantal Wood, Christopher Eccleston, Elliot Krane, George Chalkaiadis, Gustav Ljungman, Jacqui Clinch, Jeffrey Gold, Julia Wager, Marie-Claude Gregoire, Miranda van Tilburg, Navil Sethna, Neil Schechter, Phil Wiffen, Richard Howard, Susie Lord.

\section{Purpose}

National Institute for Health Research (NIHR) (UK) Programme Grant - Addressing the unmet need of chronic pain: providing the evidence for treatments of pain.

\section{Proposal}

Nine reviews in pharmacological interventions for chronic pain in children and adolescents: Children (5 new, 1 update, 1 overview, and 2 rapid) self-management of chronic pain is prioritised by the planned NICE guideline. Pain management (young people and adults) with a focus on initial assessment and management of persistent pain in young people and adults.

We propose titles in paracetamol, ibuprofen, diclofenac, other NSAIDs, and codeine, an overview review on pain in the community, 2 rapid reviews on the pharmacotherapy of chronic pain, and cancer pain, and an update of psychological treatments for chronic pain.

\section{Key outcomes}

The final titles: (1) opioids for cancer-related pain (Wiffen 2017a), (2) opioids for chronic non-cancer pain (Cooper 2017a), (3) antiepileptic drugs for chronic non-cancer pain (Wiffen 2017b), (4) antidepressants for chronic non-cancer pain (Cooper 2017b), (5) Non-steroidal antiinflammatory drugs (NSAIDs) for chronic non-cancer pain (Eccleston 2017), (6) Non-steroidal anti-inflammatory drugs (NSAIDs) for cancerrelated pain (Cooper 2017c - this review), (7) paracetamol for chronic non-cancer pain (Cooper 2017c).

\section{PICO}

Patients: children, aged 3 to 12 , chronic pain defined as pain persisting for 3 months (NB: now changed to: birth to 17 years to include infants, children and adolescents).

Interventions: by drug class including antiepileptic drugs, antidepressants, opioids, NSAIDs, and paracetamol.

Comparisons: maintain a separation of cancer and non-cancer, exclude headache, in comparison with placebo and or active control.

Outcomes: we will adopt the IMMPACT criteria. 


\section{Appendix 2. Methodological considerations for chronic pain}

There have been several recent changes in how the efficacy of conventional and unconventional treatments is assessed in chronic painful conditions. The outcomes are now better defined, particularly with new criteria for what constitutes moderate or substantial benefit (Dworkin 2008); older trials may only report participants with 'any improvement'. Newer trials tend to be larger, avoiding problems from the random play of chance. Newer trials also tend to be of longer duration, up to 12 weeks, and longer trials provide a more rigorous and valid assessment of efficacy in chronic conditions. New standards have evolved for assessing efficacy in neuropathic pain, and we are now applying stricter criteria for the inclusion of trials and assessment of outcomes, and are more aware of problems that may affect our overall assessment. We summarise some of the recent insights that must be considered in this new review.

1. Pain results tend to have a U-shaped distribution rather than a bell-shaped distribution. This is true in acute pain (Moore 2011a; Moore 2011b), back pain (Moore 2010d), and arthritis (Moore 2010c), as well as in fibromyalgia (Straube 2010); in all cases average results usually describe the experience of almost no-one in the trial. Data expressed as averages are potentially misleading, unless they can be proven to be suitable.

2. As a consequence, we have to depend on dichotomous results (the individual either has or does not have the outcome) usually from pain changes or patient global assessments. The Initiative on Methods, Measurement, and Pain Assessment in Clinical Trials (IMMPACT) group has helped with their definitions of minimal, moderate, and substantial improvement (Dworkin 2008). In arthritis, trials of less than 12 weeks' duration, and especially those shorter than eight weeks, overestimate the effect of treatment (Moore 2010c); the effect is particularly strong for less effective analgesics, and this may also be relevant in neuropathic-type pain.

3. The proportion of patients with at least moderate benefit can be small, even with an effective medicine, falling from $60 \%$ with an effective medicine in arthritis to 30\% in fibromyalgia (Moore 2009; Moore 2010c; Moore 2013b; Moore 2014b; Straube 2008; Sultan 2008). A Cochrane Review of pregabalin in neuropathic pain and fibromyalgia demonstrated different response rates for different types of chronic pain (higher in diabetic neuropathy and postherpetic neuralgia and lower in central pain and fibromyalgia) (Moore 2009). This indicates that different neuropathic pain conditions should be treated separately from one another, and that pooling should not be done unless there are good grounds for doing so.

4. Individual patient analyses indicate that patients who get good pain relief (moderate or better) have major benefits in many other outcomes, affecting quality of life in a significant way (Moore 2010b; Moore 2014a).

5. Imputation methods such as last observation carried forward (LOCF), used when participants withdraw from clinical trials, can overstate drug efficacy especially when adverse event withdrawals with drug are greater than those with placebo (Moore 2012).

\section{Appendix 3. MEDLINE search strategy (via Ovid)}

1. exp Pain/

2. pain.tw.

3. 1 or 2

4. exp Neoplasms/

5. (cancer ${ }^{\star}$ or neoplas* or tumo* or carcinoma* or hodgkin* or nonhodgkin* or adenocarcinoma* or leuk? emia* or metasta* or malignan* or lymphoma* or sarcoma* or melanoma* or myeloma* or oncolog*).tw.

6. 4 or 5

7. $\exp$ Child/ or exp adolescent/ or exp infant/

8. (child ${ }^{\star}$ or boy $^{\star}$ or girl ${ }^{\star}$ or adolescen ${ }^{\star}$ or teen ${ }^{\star}$ or toddler ${ }^{\star}$ or preschooler ${ }^{\star}$ or pre-schooler ${ }^{\star}$ or infant ${ }^{\star}$ or baby or babies ).tw.

9. 7 or 8

10.13 and 6 and 9

11.exp Anti-Inflammatory Agents, Non-Steroidal/

12.NSAID*.tw.

13."non-steroidal anti-inflammatory drug*".tw.

14.(ibuprofen or aspirin or naproxen or fenoprofen or ketoprofen or tiaprofenic acid or diclofenac or aceclofenac or etodolac or indometacin or mefenamic acid or meloxicam or nabumeton or phenylbutazone or piroxicam or sulindac or tenoxicam or tolfenamic acid or ketorolac or parecoxib or celecoxib or etoricoxib).tw.

15."non-steroidal anti-inflammatory agent ${ }^{\star}$.tw.

16.or/11-15

17.randomized controlled trial.pt.

18. controlled clinical trial.pt.

19.randomized.ab.

20.placebo.ab.

21.drug therapy.fs.

22.randomly.ab.

23.trial.ab. 
24.groups.ab.

25.17 or 18 or 19 or 20 or 21 or 22 or 23 or 24

26.exp animals/ not humans.sh.

27.25 not 26

28.10 and 16 and 27

\section{Appendix 4. Embase search strategy (via Ovid)}

1. exp Pain/

2. pain.tw.

3. 1 or 2

4. exp Neoplasms/

5. (cancer ${ }^{\star}$ or neoplas* or tumo* or carcinoma* or hodgkin* or nonhodgkin* or adenocarcinoma* or leuk?emia* or metasta* or malignan* or lymphoma* or sarcoma* or melanoma* or myeloma* or oncolog*).tw.

6. 4 or 5

7. exp Child/ or exp adolescent/ or exp infant/

8. (child ${ }^{\star}$ or boy ${ }^{\star}$ or girl* or adolescen ${ }^{\star}$ or teen ${ }^{\star}$ or toddler ${ }^{\star}$ or preschooler ${ }^{\star}$ or pre-schooler ${ }^{\star}$ or infant ${ }^{\star}$ or baby or babies).tw.

9. 7 or 8

10.3 and 6 and 9

11.exp Anti-Inflammatory Agents, Non-Steroidal/

12.NSAID*.tw.

13."non-steroidal anti-inflammatory drug*".tw.

14.(ibuprofen or aspirin or naproxen or fenoprofen or ketoprofen or tiaprofenic acid or diclofenac or aceclofenac or etodolac or indometacin or mefenamic acid or meloxicam or nabumeton or phenylbutazone or piroxicam or sulindac or tenoxicam or tolfenamic acid or ketorolac or parecoxib or celecoxib or etoricoxib).tw.

15."non-steroidal anti-inflammatory agent*".tw.

16.or/11-15

17.random\$.tw.

18. factorial\$.tw.

19.crossover\$.tw.

20.cross over\$.tw.

21.cross-over\$.tw.

22. placebo\$.tw.

23. (doubl\$ adj blind\$).tw.

24.(singl\$ adj blind\$).tw.

25.assign\$.tw.

26.allocat\$.tw.

27.volunteer\$.tw.

28. Crossover Procedure/

29.double-blind procedure.tw.

30.Randomized Controlled Trial/

31.Single Blind Procedure/

32.or/17-31

33. (animal/ or nonhuman/) not human/

34.32 not 33

35.10 and 16 and 34

Appendix 5. CENTRAL search strategy (via CRSO)

1. MESH DESCRIPTOR Pain EXPLODE ALL TREES

2. pain: $T I, A B, K Y$

3. \#1 OR\#2

4. MESH DESCRIPTOR Neoplasms EXPLODE ALL TREES

5. ((cancer ${ }^{\star}$ or neoplas* or tumo* or carcinoma* or hodgkin* or nonhodgkin* or adenocarcinoma* or leuk? emia* or metasta* or malignan ${ }^{\star}$ or lymphoma* or sarcoma* or melanoma* or myeloma* or oncolog $\left.{ }^{\star}\right)$ ):TI,AB, KY 
6. \#4 OR \#5

7. MESH DESCRIPTOR Child EXPLODE ALL TREES

8. MESH DESCRIPTOR adolescent EXPLODE ALL TREES

9. MESH DESCRIPTOR Infant EXPLODE ALL TRESS

10. ((child* or boy ${ }^{\star}$ or girl ${ }^{\star}$ or adolescen* or teen* or toddler* or preschooler* or pre-schooler ${ }^{\star}$ or infant* or baby or babies)):TI,AB,KY

11.\#7 OR \#8 OR \#9 or \#10

12.\#3 AND \#6 AND \#11

13.MESH DESCRIPTOR Anti-Inflammatory Agents, Non-Steroidal EXPLODE ALL TREES

14.NSAID*:TI,AB,KY

15.("non-steroidal anti-inflammatory drug*"):TI,AB,KY

16.((ibuprofen or aspirin or naproxen or fenoprofen or ketoprofen or tiaprofenic acid or diclofenac or aceclofenac or etodolac or indometacin or mefenamic acid or meloxicam or nabumeton or phenylbutazone or piroxicam or sulindac or tenoxicam or tolfenamic acid or ketorolac or parecoxib or celecoxib or etoricoxib)):TI,AB,KY

17.("non-steroidal anti-inflammatory agent*"):TI,AB,KY

18.\#13 OR \#14 OR \#15 OR \#16 OR \#17

19.\#12 AND \#18

\section{Appendix 6. GRADE guidelines}

Some advantages of utilising the GRADE process are (Guyatt 2008):

- transparent process of moving from evidence to recommendations;

- clear separation between quality of evidence and strength of recommendations;

- explicit, comprehensive criteria for downgrading and upgrading quality of evidence ratings; and

- clear, pragmatic interpretation of strong versus weak recommendations for clinicians, patients, and policy makers.

The GRADE system uses the following criteria for assigning grades of evidence:

- high: we are very confident that the true effect lies close to that of the estimate of the effect;

- moderate: we are moderately confident in the effect estimate; the true effect is likely to be close to the estimate of effect, but there is a possibility that it is substantially different;

- low: our confidence in the effect estimate is limited; the true effect may be substantially different from the estimate of the effect; and

- very low: we have very little confidence in the effect estimate; the true effect is likely to be substantially different from the estimate of effect.

We will decrease the grade if there is:

- serious (-1) or very serious (-2) limitation to study quality;

- important inconsistency $(-1)$;

- some (-1) or major (-2) uncertainty about directness;

- imprecise or sparse data (-1); or

- high probability of reporting bias $(-1)$.

We will increase the grade if there is:

- strong evidence of association - significant relative risk of $>2(<0.5)$ based on consistent evidence from two or more observational studies, with no plausible confounders (+1);

- very strong evidence of association - significant relative risk of $>5(<0.2)$ based on direct evidence with no major threats to validity $(+2)$;

- evidence of a dose response gradient $(+1)$; or

- all plausible confounders would have reduced the effect $(+1)$.

"In addition, there may be circumstances where the overall rating for a particular outcome would need to be adjusted per GRADE guidelines (Guyatt 2013a). For example, if there were so few data that the results were highly susceptible to the random play of chance, or if studies used LOCF imputation in circumstances where there were substantial differences in adverse event withdrawals, one would have no confidence in the result, and would need to downgrade the quality of the evidence by three levels, to very low quality. In circumstances where no data were reported for an outcome, we planned to report the level of evidence as 'no evidence to support or refute' (Guyatt 2013b)." 
WHAT'S NEW

\begin{tabular}{lll}
\hline Date & Event & Description \\
\hline 7 June 2019 & Amended & $\begin{array}{l}\text { We amended the GRADE methods for assessing no evidence, for } \\
\text { consistency with the other reviews in this series. Clarification } \\
\text { added to Declarations of interest. }\end{array}$ \\
\hline 31 January 2019 & Review declared as stable & See Published notes. \\
\hline
\end{tabular}

\section{H ISTORY}

Protocol first published: Issue 2, 2017

Review first published: Issue 7, 2017

\begin{tabular}{lll}
\hline Date & Event & Description \\
\hline 4 July 2018 & Amended & $\begin{array}{l}\text { Searches updated with terms relating to 'infants'. We did not } \\
\text { identify any new studies. }\end{array}$ \\
\hline 8 March 2018 & Amended & Affiliation updated. \\
\hline 14 August 2017 & Amended & $\begin{array}{l}\text { References for some reviews from the suite amended to reflect } \\
\text { correct publication Issue. }\end{array}$ \\
\hline
\end{tabular}

\section{CONTRIBUTIONS OF AUTHORS}

TC and CE registered the title.

TC, PW and CE wrote the template protocol for the suite of children's reviews of which this review is a part.

All authors contributed to writing the protocol and all authors agreed on the final version.

All authors were responsible for data extraction, analysis, and writing of the discussion for the full review.

All authors will be responsible for the completion of updates.

\section{DECLARATIONS OF INTEREST}

CE: none known. Since CE is an author as well as the PaPaS Co-ordinating Editor at the time of writing, we acknowledge the input of Leontien Kremer, of the Cochrane Childhood Cancer Group, who acted as Sign Off Editor for this review. CE had no input into the editorial decisions or processes for this review.

TC: none known.

BA: none known; BA is a specialist anaesthetist and intensive care physician and manages the perioperative care of children requiring surgery and those critically ill requiring intensive care.

MCG: none known; MCG is a specialist paediatric pain and palliative care physician and treats patients with complex pain.

LH: none known.

GL: none known; GL is a specialist paediatric oncologist and paediatric pain physician and manages patients with cancer and cancer pain. 


\section{SOURCES OF SUPPORT}

\section{Internal sources}

- No sources of support supplied

\section{External sources}

- National Institute for Health Research (NIHR), UK.

NIHR Programme Grant, Award Reference Number: 13/89/29 (Addressing the unmet need of chronic pain: providing the evidence for treatments of pain)

\section{DIFFERENCES BETWEEN PROTOCOL AND REVIEW}

We altered the MEDLINE search strategy after some discussion with the Cochrane Childhood Cancer Group. The search strategies for Embase and CENTRAL were then modelled on the minor changes.

Minor changes to background wording and details of examples.

Studies with < 10 participants per treatment arm were not considered for inclusion in this review, as is standard practice for this group.

\section{NOTES}

A restricted search in January 2019 did not identify any potentially relevant studies likely to change the conclusions. Therefore, this review has now been stabilised following discussion with the authors and editors. The review will be re-assessed for updating in five years. If appropriate, we will update the review before this date if new evidence likely to change the conclusions is published, or if standards change substantially which necessitates major revisions.

\section{INDEX TERMS}

\section{Medical Subject Headings (MeSH)}

Anti-Inflammatory Agents, Non-Steroidal [ ${ }^{\star}$ therapeutic use]; Cancer Pain [ ${ }^{\star}$ drug therapy]

\section{MeSH check words}

Adolescent; Child; Child, Preschool; Humans; Infant; Infant, Newborn 